\title{
Salinomycin causes migration and invasion of human fibrosarcoma cells by inducing MMP-2 expression via PI3-kinase, ERK-1/2 and p38 kinase pathways
}

\author{
SEON-MI YU and SONG JA KIM \\ Department of Biological Sciences, College of Natural Sciences, Kongju National University, Gongju, Republic of Korea
}

Received January 27, 2016; Accepted March 8, 2016

DOI: $10.3892 /$ ijo.2016.3448

\begin{abstract}
Salinomycin (SAL) is a polyether ionophore antibiotic that has recently been shown to regulate a variety of cellular responses in various human cancer cells. However, the effects of SAL on metastatic capacity of HT1080 human fibrosarcoma cells have not been elucidated. We investigated the effect of SAL on migration and invasion, with emphasis on the expression and activation of matrix metalloproteinase (MMP)-2 in HT1080 human fibrosarcoma cells. Treatment of SAL promoted the expression and activation of MMP-2 in a dose- and time-dependent manner, as detected by western blot analysis, gelatin zymography, and real-time polymerase chain reaction. SAL also increased metastatic capacities, as determined by an increase in the migration and invasion of cells using the wound healing assay and the invasion assay, respectively. To confirm the detailed molecular mechanisms of these effects, we measured the activation of phosphoinositide 3 kinase (PI3-kinase) and mitogenactivated protein kinase (MAPK)s (ERK-1/2 and p38 kinase), as detected by the phosphorylated proteins through western blot analysis. SAL treatment increased the phosphorylation of Akt and MAPKs. Inhibition of PI3-kinase, ERK-1/2, and p38 kinase with LY294002, PD98059, and SB203580, respectively, in the presence of SAL suppressed the metastatic capacity by reducing MMP-2 expression, as determined by gelatin zymography. Our results indicate that the PI3-kinase and MAPK signaling pathways are involved in migration and
\end{abstract}

Correspondence to: Professor Song Ja Kim, Department of Biological Sciences, College of Natural Sciences, Kongju National University, Daehakro 56, Gongju 32588, Republic of Korea

E-mail: ksj85@kongju.ac.kr

Abbreviations: ERK, extracellular signal regulated protein kinase; GAPDH, glyceraldehyde 3 phosphate dehydrogenase; JNK, c-Jun $\mathrm{N}$-terminal kinase; MAPK, mitogen activated protein kinase; MMP, matrix metalloproteinase; PI-3 kinase, phosphoinositide 3 kinase; RT-PCR, reverse transcriptase polymerase chain reaction; SAL, salinomycin

Key words: salinomycin, MMP-2, migration, invasion, human fibrosarcoma cells invasion of HT1080 through induction of MMP-2 expression and activation. In conclusion, SAL significantly increases the metastatic capacity of HT1080 cells by inducing MMP-2 expression via PI3-kinase and MAPK pathways. Our results suggest that SAL may be a potential agent for the study of cancer metastatic capacities.

\section{Introduction}

Two of the basic characteristics of malignant tumors are their invasiveness and metastatic ability (1). Lung cancer is the leading cause of cancer related death, and mortality due to cancer continues to rise every year $(2,3)$. Ninety percent of lung cancer cases are non-small cell lung cancer (NSCLC), and the malignancy of NSCLC is often attributed to its invasive and metastatic capacity. One of the major contributing factors for the poor prognosis of lung cancer is distant metastasis (2). The highly metastatic human fibrosarcoma HT1080 cell line, which secretes several matrix metalloproteinases (MMPs), is one of the most widely used cell lines for studying metastasis and invasiveness (3).

During metastasis, the invasion of cancer cells involves various cellular processes, including disruption of cell adhesion, degradation of the extracellular matrix (ECM) and lymph vessels, and regulation of the cell invasion of blood. Five major classes of proteases exist (serine, aspartic, cysteine, threonine, and metalloproteinases), which play important roles in the progression of cancer. Among these enzymes, MMPs are one of the major proteases involved in the degradation of ECM, and they play a critical role in metastasis (4). Previous studies have indicated that MMPs promote tumor invasion and metastasis (5), since the expression and activation of MMPs is increased in almost all human cancer cells compared to normal tissues $(6,7)$.

MMPs are synthesized in latent forms as pro-MMP (zymogen form), requiring activation for catalytic activity, and they are specifically inhibited by the endogenous inhibitor, tissue inhibitor of MMP (TIMP) (8). MMP-2 and MMP-9 have been identified as the key enzymes involved in the degradation of type IV collagen, a major component of the basement membrane (9). Numerous studies have shown that the relative expression levels of MMPs, including MMP-2 and MMP-9, appear to increase in tumorigenesis, which is associated with elevated metastasis and invasion $(11,12)$. In particular, 
overexpression of MMP-2 has been observed in more aggressive tumor cells (10). Ectopic expression of MMP-2 has been reported in different cancer cell types, including lung (11), colon (12), ovarian (13), and prostate (13) cancers.

Activation of the phosphoinositide (PI)-3 kinase/Akt pathway results in an increase of intracellular, membrane bound phosphatidylinositol-(3,4)-diphosphate (PIP2) and phosphatidylinositol-(3,4,5)-triphosphate (PIP3). PI-3 kinase/ Akt is a key enzyme in the signal transduction cascade, and it is modulated by various growth factors that regulate cell proliferation, survival, apoptosis, growth, migration, and metabolism $(14,15)$.

Stress-activated mitogen-activated protein kinases (MAPKs) are components of the kinase cascade that connect extracellular stimuli to specific transcription factors, thereby converting these signals into cellular responses. In mammals, there are three MAPKs, namely p38, extracellular signal regulated kinase (ERK), and c-jun N-terminal kinase (JNK), and their activation is correlated with MMP-2 expression.

Salinomycin (SAL) is a polyether ionophore with antimicrobial and anticoccidial properties that has been used as an agricultural antibiotic (16). Although previous studies have investigated the effects of SAL on cancer cell growth (17), chemoresistance, and stemness in various types of cancer cells, the mechanisms by which SAL regulates MMP-2 expression remain to be elucidated. Because of the poor prognosis of metastatic fibrosarcoma HT1080, there is an urgent need to understand the regulatory mechanisms and factors related to the migration and invasion of HT1080 cells. Therefore, the aim of the present study was to evaluate the metastatic effect of SAL and to elucidate the molecular mechanisms of these effects in HT1080 human fibrosarcoma cells.

\section{Materials and methods}

Cell culture. Human fibrosarcoma HT1080 cells were obtained from the Korean cell line bank (KCLB no. 10121, Seoul, Korea). The cells were maintained in Roswell Park Memorial Institute (RPMI)-1640 (Gibco-Invitrogen, Carlsbad, CA, USA) medium supplemented with $10 \%$ fetal bovine serum (FBS), $100 \mathrm{U} / \mathrm{ml}$ penicillin, and $100 \mathrm{U} / \mathrm{ml}$ streptomycin in a humid atmosphere of $5 \% \mathrm{CO}_{2}$ and $95 \%$ air at $37^{\circ} \mathrm{C}$.

3-(4,5-Dimethylthiazol-2-yl)-2,5-diphenyltetrazolium bromide (MTT) assay. The HT1080 cells were plated into 96-well plates $\left(1 \times 10^{4}\right.$ cells/well for cells in $100 \mu \mathrm{l}$ of medium). After an overnight incubation, the cells were treated with gradient concentrations of $\operatorname{SAL}(0,1,2$, or $5 \mu \mathrm{M})$ for $24 \mathrm{~h}$ or with $5 \mu \mathrm{M}$ SAL for the indicated time periods, and then washed with phosphate-buffered saline (PBS). Thereafter, the medium was replaced with fresh medium $(200 \mu \mathrm{l})$ containing $0.5 \mathrm{mg} /$ $\mathrm{ml} \mathrm{MTT}$, and the mixture was incubated for $4 \mathrm{~h}$ at $37^{\circ} \mathrm{C}$. Following incubation, $150 \mu 1$ of dimethyl sulfoxide (DMSO) was added to each well to terminate the MTT reaction and to dissolve the formazan crystals. Subsequent to agitation for $1 \mathrm{~h}$ at room temperature, the optical density of the cells in each well was measured at $570 \mathrm{~nm}$ using a microplate reader (Molecular Devices, Sunnyvale, CA, USA). Percentage of cell viability was calculated based on untreated HT1080 (control) cells assigned $100 \%$ viability.
Wound healing assay. For detection of HT1080 cell migration, a scratch assay of the HT1080 cells was performed. In total, $2 \times 10^{5}$ cells/well HT1080 cells were seeded into 35-mm culture dishes. The cells were cultured overnight and scraped using a 10- $\mu 1$ pipette tip to create a straight-line scratch. The remaining cells were washed with medium and incubated with SAL in the absence or presence of inhibitors for $24 \mathrm{~h}$. Images of the scratch were then captured at $24 \mathrm{~h}$, and the images were quantitatively analyzed using ImageJ software (National Institutes of Health, Bethesda, MD, USA). The distance between the edges of the scratch were measured and statistically analyzed.

Invasion assay. The invasive ability of HT1080 cells was detected using the Transwell system, which consisted of 24-wells, an 8- $\mu \mathrm{m}$ pore size Transwell filter, and a polycarbonate membrane coated with Matrigel (Corning Inc., Corning, NY, USA). Initially, serum-free Dulbecco's modified Eagle's medium (DMEM) diluted Matrigel matrix (60 $\mu \mathrm{g} / \mathrm{well})$ was put into the upper chamber of the Transwell filter and incubated for $4 \mathrm{~h}$ at $37^{\circ} \mathrm{C}$ for gelling. Subsequently, the cells were trypsinized, and $2 \times 10^{5}$ cells in $100 \mu 1$ serum-free medium with or without SAL were added to each upper chamber. Following incubation for $24 \mathrm{~h}$, the cells attached to the upper surface of the membrane were removed with cotton swabs. Cells that had migrated to the underside of the insert membrane were fixed with methanol and dried. The cells were then stained for $20 \mathrm{~min}$ with $1 \mathrm{mg} / \mathrm{ml}$ crystal violet, rinsed in deionized water, air-dried, and observed under a microscope (Olympus BX50 microscope, Tokyo, Japan). At least 20 random fields were counted per filter. Each experiment was performed in triplicate and repeated at least twice.

Flow cytometry analysis. In total, $2 \times 10^{5}$ cells/well were seeded into $35-\mathrm{mm}$ culture dishes and starved in serum-free medium at $37^{\circ} \mathrm{C}$. Subsequent to a $12-\mathrm{h}$ starvation period, the cells were treated with SAL. The cells were then trypsinized and washed with PBS prior to being suspended in cold propidium iodide (PI) solution $(50 \mu \mathrm{g} / \mathrm{ml})$ containing RNase A $(0.1 \mathrm{mg} / \mathrm{ml})$ in PBS (pH 7.4) for $30 \mathrm{~min}$ in the dark. The DNA content of the cells was analyzed using a FACScaliber flow cytometer (BD Biosciences, Franklin Lakes, NJ, USA), and the data were analyzed by using BD FACStation software (BD Biosciences).

Western blot analysis. The cells were collected and the total cell lysates were prepared using cold radio immunoprecipitation assay (RIPA) buffer (50 mM Tris- $\mathrm{HCl}, \mathrm{pH} 7.4$, $150 \mathrm{mM} \mathrm{NaCl}, 1 \%$ nonidet $\mathrm{P}-40$, and $0.1 \%$ sodium dodecyl sulfate (SDS) supplemented with protease inhibitors $(10 \mu \mathrm{g} / \mathrm{ml}$ leupeptin, $10 \mu \mathrm{g} / \mathrm{ml}$ pepstatin $\mathrm{A}, 10 \mu \mathrm{g} / \mathrm{ml}$ aprotinin, and $1 \mathrm{mM}$ of 4-[2-aminoethyl] benzenesulphonyl fluoride) and phosphatase inhibitors $\left(1 \mathrm{mM} \mathrm{NaF}\right.$ and $\left.1 \mathrm{mM} \mathrm{Na}_{3} \mathrm{VO}_{4}\right)$. Cell lysate was centrifuged at $13,000 \mathrm{rpm}$ for $10 \mathrm{~min}$ at $4^{\circ} \mathrm{C}$. The protein concentration was then measured according to the bicinchoninic acid (BCA) method, with bovine serum albumin (BSA) as the standard. Next, 20-40 $\mu \mathrm{g}$ equal amounts of whole cell lysates were resolved on 8-12\% SDS-polyacrylamide gel electrophoresis (PAGE) at constant voltage and then transferred to a nitrocellulose membranes. The membranes were incubated in blocking buffer composed of 5\% skim milk in Tris-buffered saline with Tween-20 (TBST) at room temperature for $1 \mathrm{~h}$. 
A

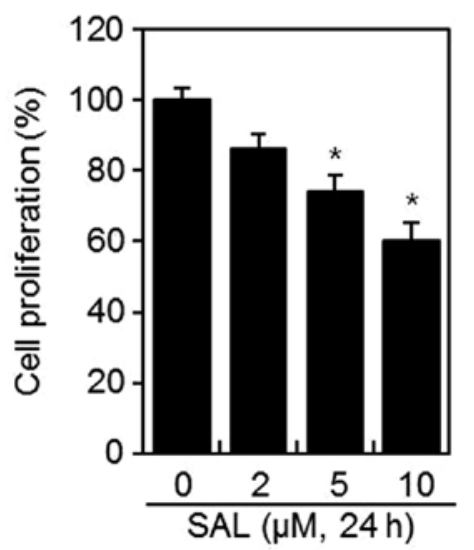

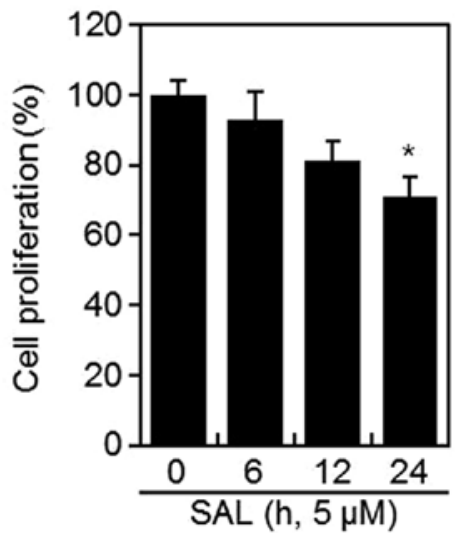

SAL $(24 \mathrm{~h}, \mu \mathrm{M})$

B

\section{2}

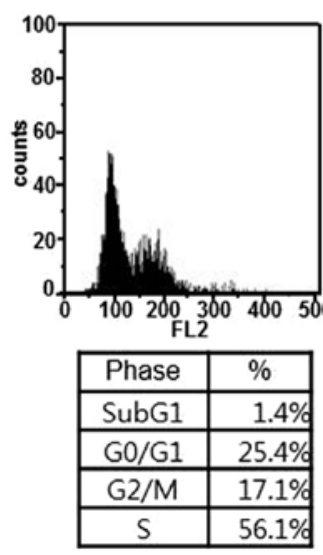

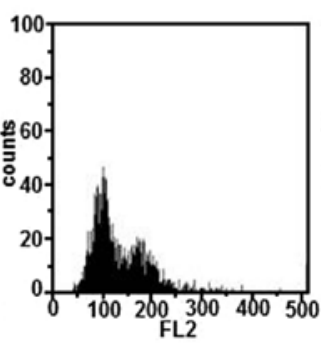
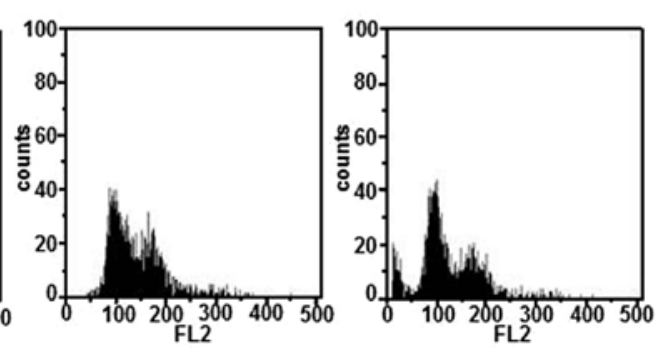

\begin{tabular}{|c|r|}
\hline Phase & \multicolumn{1}{|c|}{$\%$} \\
\hline SubG1 & 1.3 \\
\hline G0/G1 & 28.4 \\
\hline G2/M & 19.5 \\
\hline S & 50.8 \\
\hline
\end{tabular}

\begin{tabular}{|c|r|}
\hline Phase & \multicolumn{1}{|c|}{$\%$} \\
\hline SubG1 & 1.7 \\
\hline G0/G1 & 26.2 \\
\hline G2/M & 26.1 \\
\hline S & 46 \\
\hline
\end{tabular}

\begin{tabular}{|c|c|}
\hline Phase & $\%$ \\
\hline SubG1 & 16.4 \\
\hline G0/G1 & 20.7 \\
\hline G2/M & 17.6 \\
\hline S & 45.3 \\
\hline
\end{tabular}

Figure 1. Effects of salinomycin (SAL) on the cell proliferation of HT1080 cells. (A) HT1080 cells were untreated or treated with the indicated concentrations of SAL for $24 \mathrm{~h}$ (left panel) or with $5 \mu \mathrm{M}$ SAL for the indicated time periods (right panel). Cell proliferation was determined by MTT assay. (B) HT1080 cells were untreated or treated with the indicated concentrations of SAL for $24 \mathrm{~h}$. Cell cycle, DNA distribution was performed by FACS analysis. The data are representative results of three similar experiments and the means $\pm \mathrm{SD} .{ }^{*} p<0.05$ compared to the control.

Next, the blocked membranes were incubated overnight with primary antibodies at $4^{\circ} \mathrm{C}$. Thereafter, the membranes were washed with TBST three times for $10 \mathrm{~min}$ each and then incubated with secondary antibodies at room temperature for $2 \mathrm{~h}$. The blots were also incubated with a polyclonal mouse antihuman glyceraldehyde-3-phosphate dehydrogenase (GAPDH) antibody, which acted as an internal control for the quantity of target protein. Subsequent to washing in TBST, immunoreactive bands were visualized under image analyzer (LAS-4000, FujiFilm, Tokyo, Japan) using an enhanced chemiluminescence kit (Dogen, Seoul, Korea).

Zymographic assay for gelatinase. Gelatinase activity in the conditioned media was determined by gelatin zymography, as previously described (18). Cell conditioned medium was electrophoresed using 7.5\% SDS-PAGE containing 0.1\% $(\mathrm{w} / \mathrm{v})$ gelatin under non-reducing conditions and without boiling. Gels were washed twice with $2.5 \%$ (v/v) triton X-100 for $20 \mathrm{~min}$ at room temperature and subsequently incubated overnight at $37^{\circ} \mathrm{C}$ in a developing buffer containing $10 \mathrm{mM}$ $\mathrm{CaCl}_{2}, 150 \mathrm{~mm} \mathrm{NaCl}$, and $50 \mathrm{mM}$ Tris-HCl, $\mathrm{pH}$ 8.0. The gels were then stained with $0.5 \%$ Coomassie Brilliant Blue R-250 in $10 \%$ acetic acid (v/v) and 50\% methanol. The gels were destained with 50\% methanol and $10 \%$ acetic acid solution, scanned, and subjected to densitometry analysis using ImageJ software.

$R N A$ isolation and real-time polymerase chain reaction (RT-PCR) analysis. Total cellular RNA was extracted from treated cells using TRIzol reagent (Gibco). Total RNA $(0.5 \mu \mathrm{g})$ was used for cDNA synthesis with the maxime RT-PCR Premix kit (Intron, Seongnam, Republic of Korea). PCR was carried out in Takara thermal cycler dice (Takara Bio, Inc., Shiga, Japan) to amplify MMP-2 and GAPDH mRNA. Primer sequences used to amplify the desired cDNA were as follows: MMP-2 (forward primer: GCC TGA GCT CCC GGA AAA GAT TG, reverse primer: CAG CAG CCT AGC CAG TCG GAT TT), GAPDH (forward primer: CGT CTT CAC CAC CAT GGA GA, reverse primer: CGG CCA TCA CGC CAC AGT TT). PCR products electrophoresed on $2 \%$ agarose gels were visualized by ethidium bromide staining.

Statistical analysis. Data are presented as means \pm standard error of the mean (SEM) [means \pm standard deviation (SD) in the results] from at least three independent experiments and evaluated by analysis of variance (ANOVA) followed by Tukey's post-hoc test. Values of $p<0.05$ were considered statistically significant. 
A

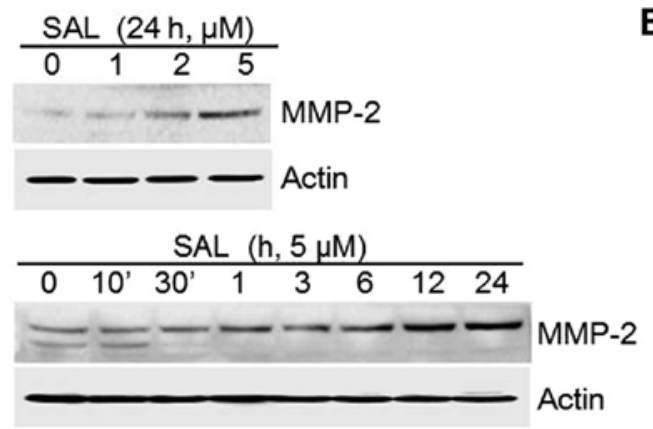

B
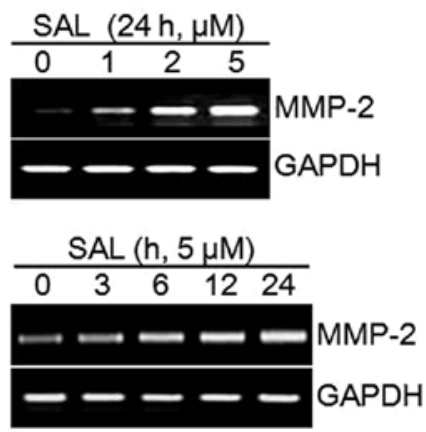

C
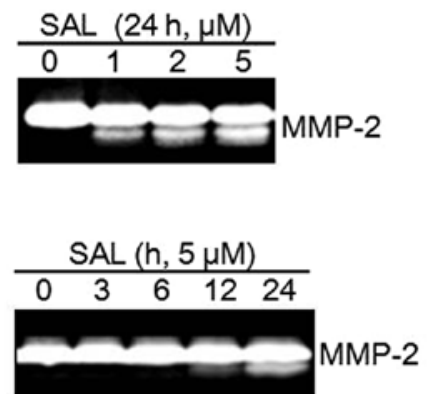
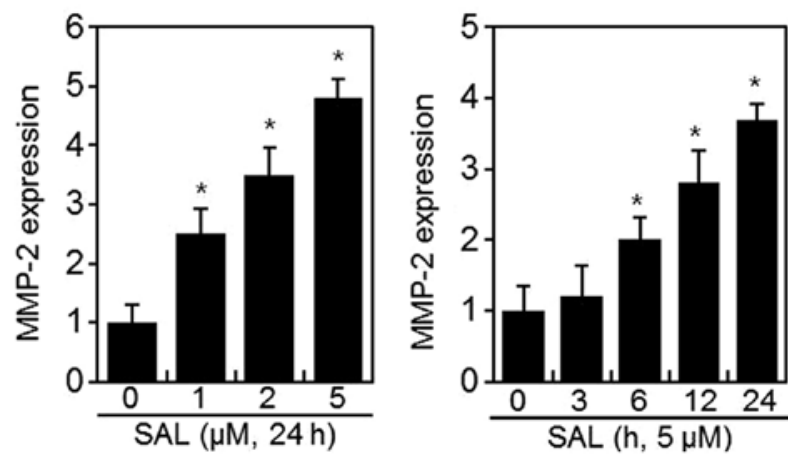

Figure 2. Effects of SAL on activation and expression of matrix metalloproteinase (MMP)-2 in HT1080 cells. (A and B) HT1080 cells were untreated or treated with the indicated concentrations of SAL for $24 \mathrm{~h}$ (upper panel) or with $5 \mu \mathrm{M}$ SAL for the indicated time periods (lower panel). (A) Expression of MMP-2 was detected using western blot analysis. Actin was used as a loading control. (B) Expression level of MMP-2 was determined using reverse transcriptasepolymerase chain reaction (RT-PCR). GAPDH was used as a loading control. (C) The activation of MMP-2 was determined using a gelatin zymography assay. The relative amounts of MMP-2 were quantified by densitometric measurement (ImageJ) (right graphs). The data are representative results of three similar experiments and the means \pm SD. ${ }^{*} p<0.05$ compared to the control.

\section{Results}

SAL inhibits proliferation of HT1080 cells. To determine the effect of SAL on HT1080 cells, an MTT assay was performed to measure cellular proliferation (Fig. 1). HT1080 cells were treated with the various concentrations of SAL for $24 \mathrm{~h}$ (Fig. 1). As shown in Fig. 1A, the proliferation of cells treated with SAL was significantly lower than that of the control cells. SAL suppressed proliferation in a dose- and time-dependent manner (Fig. 1). Flow cytometry was also used to determine the ability of SAL to induce cell cycle arrest or affect the cell cycle distribution of HT1080 cells (Fig. 1B). Compared to control cells, cells treated with SAL exhibited increased $\mathrm{G}_{2} / \mathrm{M}$ arrest at $\sim 5 \mu \mathrm{M}$, which was caused by a decrease in the ratio of $\mathrm{S}$ phase cells and an increase in the ratio of subG1 phase cells at $10 \mu \mathrm{M}$ (Fig. 1B). Next, HT1080 cells were treated with 1, 2, or $5 \mu \mathrm{M}$ SAL to study the effect of SAL on the migration and invasion on these cells. We found that SAL decreased proliferation in a dose-dependent manner, with cytotoxic effects identified at $10 \mu \mathrm{M}$ SAL, indicating an inhibitory effect of SAL on cell proliferation. Therefore, all of the obtained data were corrected by the ratio of proliferation.

SAL increases migration and invasion via MMP-2 expression and activation. Since MMP-2 and MMP-9 play a pivotal role in tumor cell invasiveness, we determined the effect of SAL on MMP-2 and MMP-9 enzyme activities. Gelatin zymography and western blot analysis were performed in order to investigate the effect of SAL on MMP-2/-9 activity and expression (Fig. 2). We confirmed that SAL induced MMP-2 expression in a dose- and time-dependent manner, as determined by western blot analysis (Fig. 2A). However, SAL did not affect activity or the expression of MMP-9 enzyme (data not shown). The mRNA level of MMP-2 was measured by quantitative RT-PCR (Fig. 2B). SAL treatment increased MMP-2 mRNA within 3 h (Fig. 2B, lower panel).

The results from gelatin zymography were consistent with the results found in western blot analysis, as described above. SAL significantly induced MMP-2 activity in a doseand time-dependent manner. The active bands of MMP-2 gradually increased when cells were treated with increasing concentrations of SAL (from 1 to $5 \mu \mathrm{M}$, Fig. 2C).

To determine whether SAL affected the motility of HT1080 cells, migration and scratch assays were performed (Fig. 3). Confluent monolayers of cells were wounded with a uniform scratch, washed to remove debris, and incubated in the absence or presence of SAL for $24 \mathrm{~h}$ (Fig. 3A). The result of the scratch assay revealed that the wound closure level, which corresponds to the wound healing ability, was significantly increased in a dose-dependent manner compared with the untreated control cells (Fig. 3A). The invasion assay showed that the number of cells that had invaded through the Matrigel-coated polycarbonate membrane was significantly increased in SAL treated cells compared to that of the control cells. These data were corrected by the ratio of proliferation (Fig. 3B). The results indicated that SAL increased the invasion and migratory capacity of HT1080 cells (Fig. 3).

SAL induces MMP-2 expression via PI-3 kinase/Akt and MAPKs pathways. Several studies have indicated that the PI-3 
A

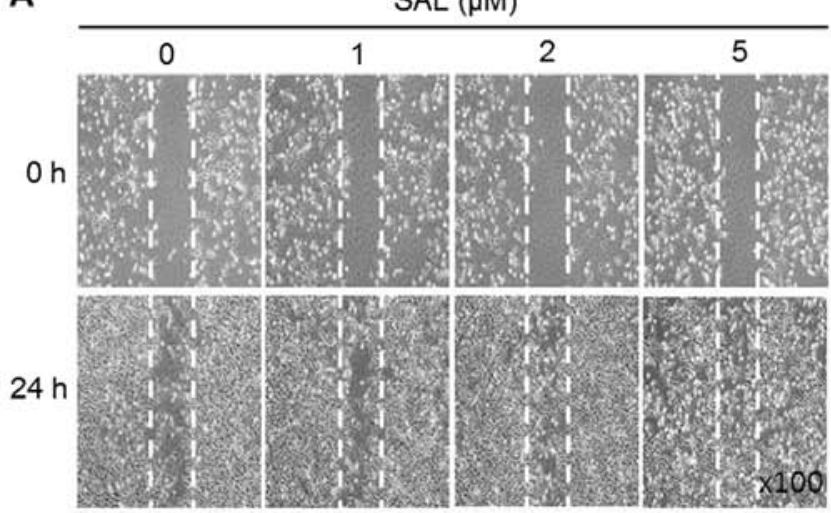

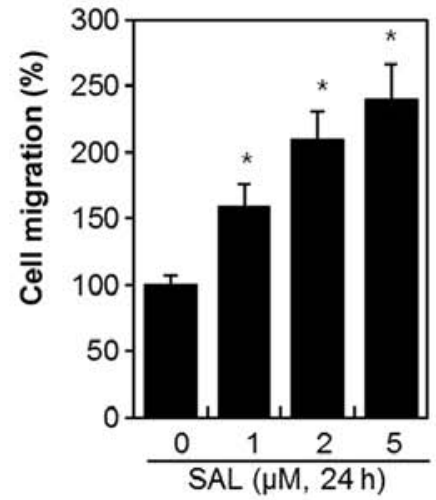

B

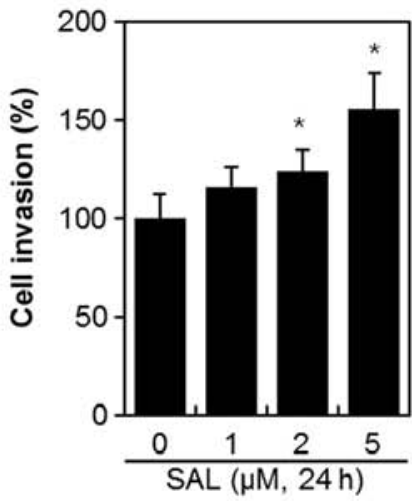

Figure 3. Effects of SAL on the cell migratory ability of HT1080 cells. (A and B) Confluent cell monolayers were scraped and then untreated or treated with the indicated concentrations of SAL for $24 \mathrm{~h}$. (A, left panel) Cell migratory ability was determined by wound healing assay. (A, right panel) The migrated cells were quantified by densitometric measurement (ImageJ). (B) The invasion ability was determined by invasion assay. The data are representative results of three similar experiments and the means \pm SD. ${ }^{*} p<0.05$ compared to the control.
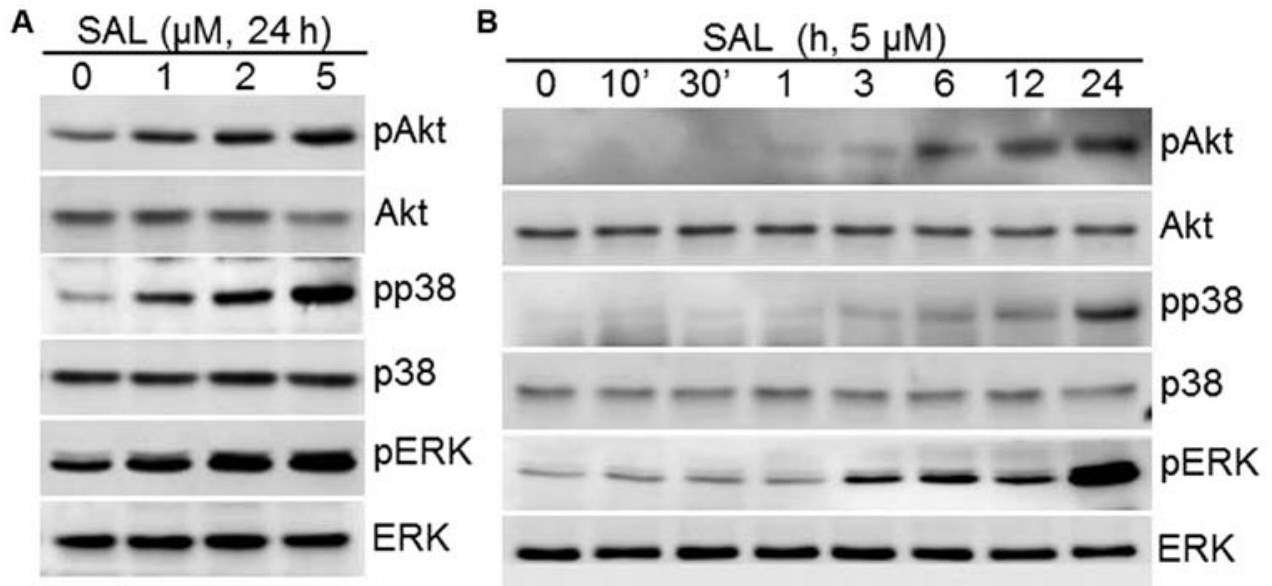

Figure 4. Effects of SAL on the activation of PI-3 kinase, p38 kinase, and ERK-1/2 in HT1080 cells. HT1080 cells were untreated or treated with the indicated concentration of SAL for $24 \mathrm{~h}$ (A) or with $5 \mu \mathrm{M} \mathrm{SAL}$ for the indicated time periods (B). The expression of pAkt, Akt, pp38, p38, pERK, and ERK was detected using western blot analysis. The data are representative results of three similar experiments.

kinase and MAPK pathways are involved in regulating the activity of MMP-2 in various cell types. To assess whether SAL regulates PI-3 kinase and MAPK pathways, we investigated the phosphorylation status of PI-3 kinase/Akt and MAPKs (ERK-1/2, p38, and JNK) in HT1080 cells after treatment with various concentrations of SAL for $24 \mathrm{~h}$ (Fig. 4A) or $5 \mu \mathrm{M}$ SAL at different time periods (Fig. 4B). As shown in Fig. 4, SAL significantly increased the phosphorylation of PI-3 kinase/Akt and the MAPKs, ERK-1/2 and p38 kinase (Fig. 4). Phosphorylated JNK was not detected in SAL-treated cells (data not shown).

To verify that the PI-3 kinase and MAPKs pathway are involved in SAL induced migration and invasion, cells were treated with PI-3 kinase and MAPK pathway inhibitors in addition to SAL (Fig. 5), and inhibition of PI-3 kinase and MAPK pathways with LY294002 (LY), PD98059 (PD), or SB203580 (SB) abolished SAL-induced MMP-2 expression, migration, and invasion (Fig. 5). Taken together, our data suggest that the PI-3 kinase and MAPK (ERK-1/2, and p38 kinase) pathways are involved in SAL-induced MMP-2 expression, migration, and invasion in HT-1080 cells.

\section{Discussion}

Tumor cell metastasis and invasion are known to involve complex cascades of events with multiple steps such as cell adhesion, ECM component degradation, and tumor cell migration. Degradation of the ECM molecules is accompanied by activation of proteolytic enzymes (19), including MMPs. MMP-2s play a pivotal role in invasion and metastasis of tumor (20,21), including human fibrosarcoma HT1080 cells. The HT1080 cells have been used extensively in the study of the ECM proteins involved in attachment, invasion, and metastasis (22-24). Thus, among the four human fibrosarcoma cell lines (SW684, Hs913T, HT1080 and 8387), the HT1080 cell line is the most frequently studied.

SAL regulates cell proliferation, survival, growth, as well as anti-tumorigenesis. However, the effect of SAL on migration and invasion of HT1080 cells had not been well elaborated. In the present study, we investigated the effect of SAL on the expression and activation of MMP-2 and MMP-9 from HT1080 cells using western blot analysis and zymography. Although we detected no effect of SAL on MMP-9 expression 
A

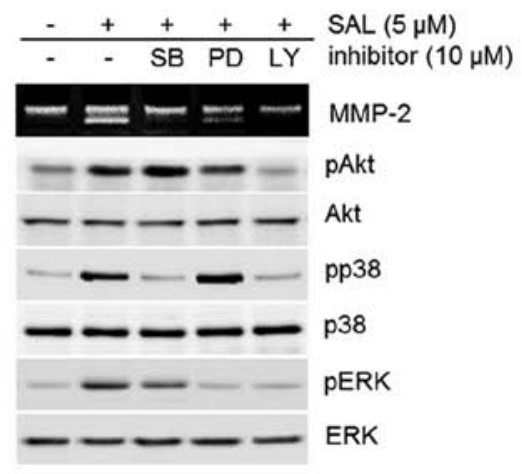

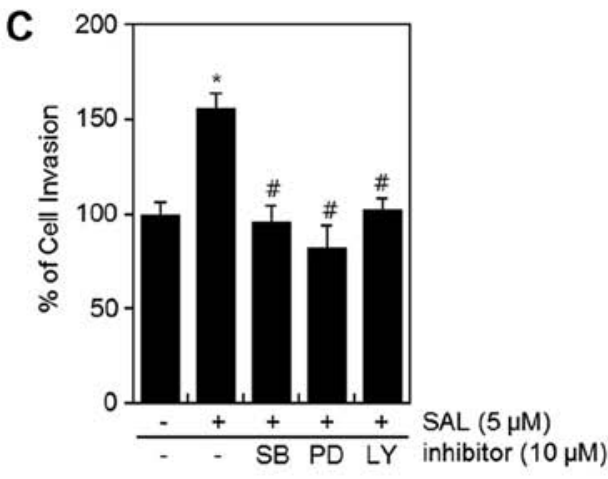

B
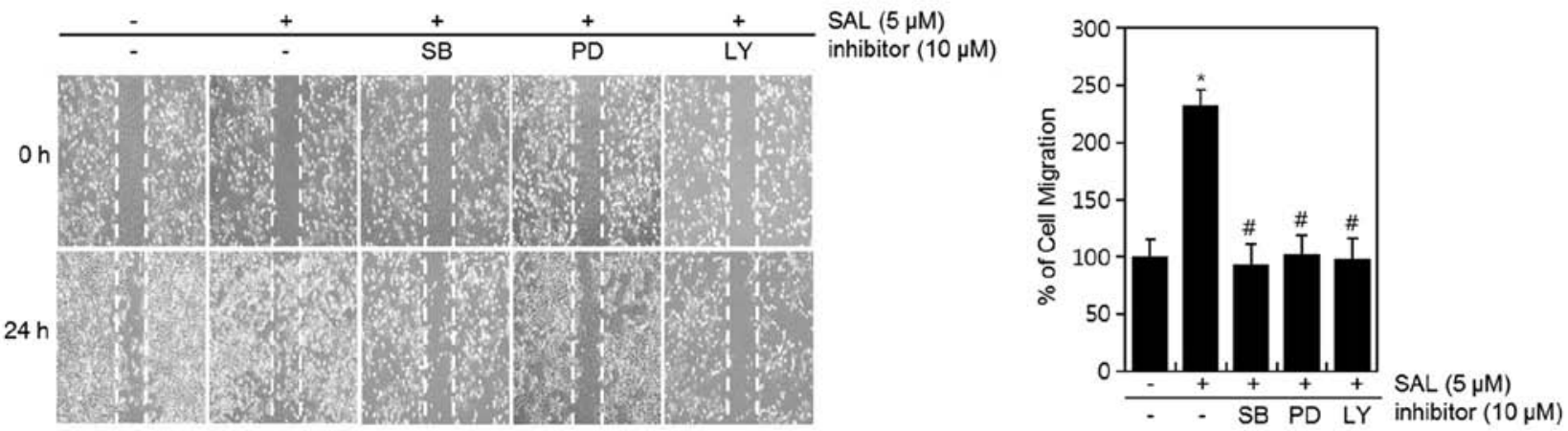

Figure 5. Effects of SAL on the cell metastatic and invasive abilities via PI-3 kinase, p38 kinase, and ERK-1/2 in HT1080 cells. (A-C) HT1080 cells were untreated or treated with SAL in the absence or presence of the inhibitor (p38 kinase; SB203580, ERK-1/2; PD98059, PI-3 kinase; LY294002). (A) The activation of MMP-2 was determined using a gelatin zymography assay, and the expression of pAkt, Akt, pp38, p38, pERK, and ERK was detected using western blot analysis. (B) Cell migratory ability was determined by wound healing assay. (C) Invasion ability was determined by invasion assay. The migrated cells were quantified by densitometric measurement. The data are representative results of three similar experiments and the means $\pm \mathrm{SD}$. ${ }^{*} p<0.05$ compared to the control. ${ }^{\#} p<0.05$ compared to the SAL-treated cells.

(data not shown), we found that MMP-2 played critical roles in cell invasion, as this enzyme degrades type IV collagen, a major component of the basement membrane (25). In our study, SAL effectively promoted the migration and invasion of HT1080 cells and induced the secretion of MMP-2 enzyme in the serum-free conditioned medium of HT1080 cells in a dose- and time-dependent manner (Fig. 2).

It was shown previously that SAL exhibited anti-metastatic properties in breast (26) and gastric cancers (27) and induced apoptosis in breast cancer (26). In contrast, our data suggest that SAL has potent pro-metastatic effects in HT1080 cells and increases apoptosis at doses $\geq 10 \mu \mathrm{M}$. The initial invasive action of metastatic cells is related to the interaction between tumor cells and ECM molecules via the progression of cell matrix adhesion $(28,29)$. The invasion assay results revealed that SAL significantly induced adhesion to Matrigel, leading us to identify which ECM molecules in Matrigel were increased by SAL.

To understand the signal pathways involved in SAL-induced migration and invasion by activation of MMP-2, we investigated the possible involvement of the PI-3 kinase and MAPK (p38 kinase and ERK-1/2) pathways. PI-3 kinases are a subgroup of the PI-3 kinase family that is activated by receptor tyrosine kinases. Their primary role is to convert PIP2 to PIP3 (30). PIP2 and PIP3 are generally absent in resting cells, but their intracellular concentration increases markedly upon stimulation via a variety of cell surface receptors, suggesting a second messenger function. The accumulation of PIP3 recruits the proto-oncogene Akt to the cell membrane, where it is phosphorylated by
PIP3-dependent kinases (PDKs) at Thr308 and Ser473 for full activation (31). Guo et al, reported that stem cell factors increase cardiac stem cell migration through PI-3 kinase/Akt and MMP-2/-9 signaling (32). Since PI-3 kinase/Akt signaling is important for cell apoptosis, survival, and mortality (33), we hypothesized that PI-3 kinase/Akt signaling is involved in the process of SAL-induced migration and invasion.

The MAPK signaling cascade, including ERK-1/2, JNK, and $\mathrm{p} 38$, has also been shown to be involved in the cellular migration of various cancer cell types (34). Inhibition of ERK-1/2 with a specific inhibitor may prevent cell migration in response to a cellular response stimulator, such as fibroblast growth factor or epidermal growth factor. Our present study showed that SAL increased the phosphorylation of ERK-1/2 and p38 kinase (Fig. 4). The MMP-2 expression in HT1080 cells induced by SAL was correlated with regulation of both the ERK-1/2 and p38 kinase pathways. However, JNK was not activated by SAL (data not shown). Taken together, our results suggest that activation of the PI-3 kinase and MAPK (p38 kinase and ERK-1/2) pathways is probably the main mechanism for altered expression and activation of MMP-2 in HT1080 cells treated with SAL. Although the exact mechanism remains unclear, the present study provides a foundation for future investigations on metastasis of HT1080 cells.

\section{Acknowledgements}

This study was supported by the National Research Foundation of Korea (NRF) grant funded by the Korea government (MSIP) 
(nos. 2015R1C1A2A01055015 and 2014R1A1A3049653) and the Korean Health Technology R\&D Project, Ministry of Health and Welfare, Republic of Korea (A120960-1201-0000300).

\section{References}

1. Franco R, Zappavigna S, Gigantino V, Luce A, Cantile M, Cerrone $M$, Facchini G, Perdonà S, Pignata $S$, Di Lorenzo G, et al: Urotensin II receptor determines prognosis of bladder cancer regulating cell motility/invasion. J Exp Clin Cancer Res 33: 48, 2014

2. Molina JR, Yang P, Cassivi SD, Schild SE and Adjei AA: Non-small cell lung cancer: Epidemiology, risk factors, treatment, and survivorship. Mayo Clin Proc 83: 584-594, 2008.

3. Fisher KE, Pop A, Koh W, Anthis NJ, Saunders WB and Davis GE: Tumor cell invasion of collagen matrices requires coordinate lipid agonist-induced G-protein and membrane-type matrix metalloproteinase-1-dependent signaling. Mol Cancer 5: 69, 2006.

4. Kessenbrock K, Plaks V and Werb Z: Matrix metalloproteinases: Regulators of the tumor microenvironment. Cell 141: 52-67, 2010.

5. Stamenkovic I: Matrix metalloproteinases in tumor invasion and metastasis. Semin Cancer Biol 10: 415-433, 2000.

6. Forget MA, Desrosiers RR and Béliveau R: Physiological roles of matrix metalloproteinases: Implications for tumor growth and metastasis. Can J Physiol Pharmacol 77: 465-480, 1999.

7. Curran S, Dundas SR, Buxton J, Leeman MF, Ramsay R and Murray GI: Matrix metalloproteinase/tissue inhibitors of matrix metalloproteinase phenotype identifies poor prognosis colorectal cancers. Clin Cancer Res 10: 8229-8234, 2004.

8. Gomez DE, Alonso DF, Yoshiji $\mathrm{H}$ and Thorgeirsson UP: Tissue inhibitors of metalloproteinases: Structure, regulation and biological functions. Eur J Cell Biol 74: 111-122, 1997.

9. Mook OR, Frederiks WM and Van Noorden CJ: The role of gelatinases in colorectal cancer progression and metastasis. Biochim Biophys Acta 1705: 69-89, 2004.

10. Koshiba T, Hosotani R, Wada M, Miyamoto Y, Fujimoto K, Lee JU, Doi R, Arii S and Imamura M: Involvement of matrix metalloproteinase-2 activity in invasion and metastasis of pancreatic carcinoma. Cancer 82: 642-650, 1998.

11. Guo CB, Wang S, Deng C, Zhang DL, Wang FL and Jin XQ: Relationship between matrix metalloproteinase 2 and lung cancer progression. Mol Diagn Ther 11: 183-192, 2007.

12. Papadopoulou S, Scorilas A, Arnogianaki N, Papapanayiotou B, Tzimogiani A, Agnantis $\mathrm{N}$ and Talieri M: Expression of gelatinase-A (MMP-2) in human colon cancer and normal colon mucosa. Tumour Biol 22: 383-389, 2001.

13. Björklund $M$ and Koivunen E: Gelatinase-mediated migration and invasion of cancer cells. Biochim Biophys Acta 1755: 37-69, 2005.

14. Engelman JA, Luo J and Cantley LC: The evolution of phosphatidylinositol 3-kinases as regulators of growth and metabolism. Nat Rev Genet 7: 606-619, 2006.

15. García Z, Kumar A, Marqués M, Cortés I and Carrera AC: Phosphoinositide 3-kinase controls early and late events in mammalian cell division. EMBO J 25: 655-661, 2006.

16. Naujokat C, Fuchs D and Opelz G: Salinomycin in cancer: A new mission for an old agent. Mol Med Rep 3: 555-559, 2010.

17. Jayapalan JJ, Ng KL, Razack AH and Hashim OH: Identification of potential complementary serum biomarkers to differentiate prostate cancer from benign prostatic hyperplasia using gel- and lectin-based proteomics analyses. Electrophoresis 33: 1855-1862, 2012.
18. Herr MJ, Kotha J, Hagedorn N, Smith B and Jennings LK: Tetraspanin CD9 promotes the invasive phenotype of human fibrosarcoma cells via upregulation of matrix metalloproteinase-9. PLoS One 8: e67766, 2013.

19. Nelson AR, Fingleton B, Rothenberg ML and Matrisian LM: Matrix metalloproteinases: Biologic activity and clinical implications. J Clin Oncol 18: 1135-1149, 2000.

20. Chung TW, Moon SK, Lee YC, Kim JG, Ko JH and Kim CH: Enhanced expression of matrix metalloproteinase-9 by hepatitis B virus infection in liver cells. Arch Biochem Biophys 408: 147-154, 2002.

21. Basset P, Okada A, Chenard MP, Kannan R, Stoll I, Anglard P, Bellocq JP and Rio MC: Matrix metalloproteinases as stromal effectors of human carcinoma progression: Therapeutic implications. Matrix Biol 15: 535-541, 1997.

22. Yamada KM, Kennedy DW, Yamada SS, Gralnick H, Chen WT and Akiyama SK: Monoclonal antibody and synthetic peptide inhibitors of human tumor cell migration. Cancer Res 50: 4485-4496, 1990.

23. Watanabe H, Carmi P, Hogan V, Raz T, Silletti S, Nabi IR and Raz A: Purification of human tumor cell autocrine motility factor and molecular cloning of its receptor. J Biol Chem 266: 13442-13448, 1991.

24. Mukaida N, Gussella GL, Kasahara T, Ko Y, Zachariae CO, Kawai T and Matsushima K: Molecular analysis of the inhibition of interleukin-8 production by dexamethasone in a human fibrosarcoma cell line. Immunology 75: 674-679, 1992.

25. Stetler-Stevenson WG: Type IV collagenases in tumor invasion and metastasis. Cancer Metastasis Rev 9: 289-303, 1990.

26. Kim S, Ding W, Zhang L, Tian W and Chen S: Clinical response to sunitinib as a multitargeted tyrosine-kinase inhibitor (TKI) in solid cancers: A review of clinical trials. Onco Targets Ther 7: 719-728, 2014.

27. Antoszczak M, Popiel K, Stefańska J, Wietrzyk J, Maj E, Janczak J, Michalska G, Brzezinski B and Huczyński A: Synthesis, cytotoxicity and antibacterial activity of new esters of polyether antibiotic - salinomycin. Eur J Med Chem 76: 435-444, 2014.

28. Ramsay AG, Marshall JF and Hart IR: Integrin trafficking and its role in cancer metastasis. Cancer Metastasis Rev 26: 567-578, 2007.

29. Luo BH, Carman CV and Springer TA: Structural basis of integrin regulation and signaling. Annu Rev Immunol 25: 619-647, 2007.

30. Vivanco I and Sawyers CL: The phosphatidylinositol 3-Kinase AKT pathway in human cancer. Nat Rev Cancer 2: 489-501, 2002.

31. Bellacosa A, Kumar CC, Di Cristofano A and Testa JR: Activation of AKT kinases in cancer: Implications for therapeutic targeting. Adv Cancer Res 94: 29-86, 2005.

32. Guo J, Jie W, Shen Z, Li M, Lan Y, Kong Y, Guo S, Li T and Zheng S: SCF increases cardiac stem cell migration through PI3K/AKT and MMP-2/-9 signaling. Int J Mol Med 34: 112-118, 2014.

33. Hou J, Wang L, Jiang J, Zhou C, Guo T, Zheng S and Wang T: Cardiac stem cells and their roles in myocardial infarction. Stem Cell Rev 9: 326-338, 2013.

34. Theodosiou A and Ashworth A: MAP kinase phosphatases. Genome Biol 3: Reviews3009, 2002. 